\title{
Characteristics of the Narrow Fractions of Fly Ash Microspheres as the Basis of Light-Weight High-Strength Materials
}

\author{
Elena S. Rogovenko*, \\ Olga A. Kushnerova and Elena V. Fomenko \\ Institute of Chemistry and Chemical Technology SB RAS \\ FRC "Krasnoyarsk Science Center SB RAS" \\ 50/24 Akademgorodok, Krasnoyarsk, 660036, Russia
}

Received 15.01.2018, received in revised form 27.02.2019, accepted 21.03.2019

\begin{abstract}
The narrow fractions of microspheres with a size of $-0.4+0.2 \mathrm{~mm}$ with a low bulk density in the range of 0.34-0.64 g/ $/ \mathrm{cm}^{3}$ were separated from cenosphere concentrates of fly ashes and fly ash from local selection obtained from pulverized coal combustion. The main components of the chemical composition in obtained narrow fractions are $\mathrm{SiO}_{2}-55-66$ and $\mathrm{Al}_{2} \mathrm{O}_{3}-21-40 \mathrm{wt}$. \%. The part of amorphous glass phase are 63-93, the mullite phase are 1-34, the quartz phase are 2-8 and the calcite phase are $0-1 \mathrm{wt} . \%$. It is found that microspheres, characterized by maximum values of bulk density $0.64 \mathrm{~g} / \mathrm{cm}^{3}$ and apparent thickness of the shell $20 \mu \mathrm{m}$, has the best strength properties. The successive twofold compressive loading the particles by increased strength were selected, for which the values of bulk density and apparent shell thickness increased to $0.86 \mathrm{~g} / \mathrm{cm}^{3}$ and $29 \mu \mathrm{m}$, respectively. It is shown that the spheres with the single-ring structure are primarily subjected to destruction; the particles with network and solid structure provide improved strength characteristics of narrow fractions of microspheres.
\end{abstract}

Keywords: microspheres, cenospheres, fly ash, narrow fraction, high-strength light-weight materials, proppant granules.

Citation: Rogovenko E.S., Kushnerova O.A., Fomenko E.V. Characteristics of the narrow fractions of fly ash microspheres as the basis of light-weight high-strength materials, J. Sib. Fed. Univ. Chem., 2019, 12(2), 248-260. DOI: 10.17516/1998-28360123 .

(C) Siberian Federal University. All rights reserved

* Corresponding author E-mail address: rogovenko_elena1989@mail.ru 


\title{
Характеристика узких фракций микросфер летучих зол как основы облегченных высокопрочных материалов
}

\author{
Е.С. Роговенко, О.А. Кушнерова, Е.В. Фоменко \\ Институт химии и химической технологии СО РАН \\ ФИЦ «Красноярский научный изентр СО РАН» \\ Россия, 660036, Красноярск, Академгородок, 50/24
}

Из концентратов иеносфер летучих зол и золь-уноса локального отбора, полученных от пылевидного сжигания углей, выделены узкие фракции микросфер размером -0.4+0.2 мм с низкой насыпной плотностью в интервале 0.34-0.64 г/см. Основными компонентами химического состава полученных узких фракций являются $\mathrm{SiO}_{2}-55-66$ и $\mathrm{Al}_{2} \mathrm{O}_{3}-21-40$ мас. \%. Доля аморфной стеклофазы составляет 63-93, фазы муллита - 1-34, квариа-2-8, кальцита0-1 мас. \%. Установлено, что лучшими прочностными показателями обладают микросферы, характеризуюшиеся максимальным значением насыпной плотности 0.64 г/см ${ }^{3}$ и кажущейся толщины оболочки 20мкм. Последовательнымдвукратнымвоздействиемсжимающейнагрузки выделены частицы повышенной прочности, для которых значения насыпной плотности и кажущейся толщины оболочки увеличились до 0.86 г/см и 29 мкм соответственно. Показано, что разрушению в первую очередь подвергаются сферы кольиевого строения, а сетчатые и массивные частицы обеспечивают улучшенные прочностные свойства узких фракиий микросфер.

Ключевые слова: микросферы, ценосферы, летучая зола, узкая фракиия, высокопрочные облегченные материалы, гранулы пропантов.

\section{Введение}

В летучих золах от пылевидного сжигания энергетических углей содержатся ценные микросферические компоненты - полые алюмосиликатные микросферы (ценосферы) [1-3], которые по своим свойствам не уступают дорогостоящим синтетическим микросферам, а в некоторых случаях их превосходят. Благодаря этому в мире большой интерес вызывают разработки технологий получения на основе микросферических компонентов, выделенных из дешевого и доступного сырья, функциональных и композитных материалов с улучшенными свойствами для различных областей применения - адсорбентов, катализаторов, носителей, керамических материалов, цеолитов [3, 4].

Необходимым условием для получения новых материалов с прогнозируемыми и воспроизводимыми свойствами является определенный химический, фазовый состав и строение используемых микросфер. Использование технологической схемы разделения, включающей стадии гранулометрического разделения, аэродинамической классификации и магнитной сепарации [5-7], позволяет получить из концентратов ценосфер летучих зол от сжигания разных типов энергетических углей узкие фракции в интервале размеров 50-250 мкм постоянного

$$
-249-
$$


химического и минерально-фазового состава с преобладающим содержанием глобул определенного морфологического типа. На их основе разработан ряд функциональных материалов, к которым относятся высокоселективные мембраны для диффузионного выделения гелия и контейнеры для хранения водорода [8-10], сенсибилизаторы эмульсионных взрывчатых веществ [11], капсулированные рН-чувствительные спиновые зонды для исследования биологических объектов [12], композитные сорбенты для извлечения радионуклидов из жидких радиоактивных отходов $[13,14]$.

Одним из перспективных направлений использования полых микросфер летучих зол, благодаря их низкой объемной плотности 0.2-0.8 г/см³ $[1,2,5-7]$, представляется получение облегченных материалов различного назначения. Новым типом легких и высокопрочных материалов являются пропанты - сферические гранулы, которые выполняют функции расклинивающего агента, предотвращая смыкание образовавшихся трещин в современной добыче нефти и газа по технологии гидравлического разрыва пласта $[15,16]$. Для более глубокого проникновения в трещину гранулы пропантов должны находиться во взвешенном состоянии, поэтому необходимо, чтобы их плотность была близка к плотности жидкости гидроразрыва. Использование облегченных пропантов позволяет применять менее концентрированные жидкости гидроразрыва, а в некоторых случаях (при использовании гранул с плотностью $\leq 1$ г/см³) проведение гидравлического разрыва пласта и доставка пропанта может быть осуществлена водой.

Традиционный способ уменьшения насыпной плотности расклинивающих гранул - введение в их состав различных наполнителей, в том числе полых стеклянных или керамических микросфер [16, 17]. Однако, такой подход рассматривает полые микросферы только как компонент низкой плотности без учета их состава и особенностей строения и тем самым исключает возможность направленного воздействия на физико-химические характеристики получаемых материалов и практического управления их свойствами.

Целью работы стало выделение из летучих зол узких фракций микросфер для целенаправленного получения сферических гранул пропантов, определение их физико-химических характеристик, установление взаимосвязи состав - строение - прочностные свойства микросфер и оценка перспективности использования микросфер как основы облегченных высокопрочных материалов.

\section{Экспериментальная часть}

В качестве сырья для получения узких фракций микросфер размером $-0.4+0.2$ мм использовали концентраты ценосфер летучих зол алюмокремнистого (Sialic) типа, полученные от пылевидного сжигания разных типов энергетических углей на крупных тепловых станциях России: каменного угля Кузнецкого бассейна марок Г и Д на Новосибирской ТЭЦ-5 (фракция Н) и марки Т на Московской ТЭЦ-22 (фракция М), каменного угля марки СС Экибастузского бассейна на Рефтинской ГРЭС (фракции R, HM-R-5A, R/A25 GG), а также золу-уноса локального отбора 1 поля электрофильтра Рефтинской ГРЭС (фракция R/B16 GG).

Выделение узких фракций микросфер проводили с использованием технологической схемы [5-7, 18], включающей стадии аэродинамического разделения, гранулометрической классификации, магнитной сепарации, разделения по плотности в гексане, гидростатического 
отделения разрушенных и перфорированных глобул. Стадия аэродинамического разделения была реализована на центробежном лабораторном классификаторе 50 ATP (Hosokawa ALPINE, Германия), позволяющем получать однородные фракции с определенным максимумом распределения. Подробно схема классификатора и принцип его действия изложены в работе [18]. На стадии гранулометрической классификации для разделения глобул по размеру с высокой воспроизводимостью была использована установка воздушно-ситового просеивания е200 LS (Hosokawa ALPINE, Германия). Магнитная сепарация была проведена на лабораторном электромагнитном сепараторе СЭМ-1 (Россия).

Для каждой полученной узкой фракции были определены следующие физико-химические параметры: химический и фазовый составы, насыпная плотность, распределение по размерам, средний диаметр глобул, кажущаяся толщина оболочки, содержание глобул определенного морфологического типа. Подробные методики определения этих параметров, включая контроль чистоты выделенных фракций, приведены в работах [5-7, 9].

Химический состав, включающий содержание оксидов кремния, алюминия, железа, кальция, магния, калия и натрия, а также потери при прокаливании (п.п.п.), определяли методами химического анализа согласно ГОСТ 5382-91 [19], устанавливающего методики определения компонентов и нормы точности выполнения анализов. Фазовый состав выявляли с применением полнопрофильного анализа по методу Ритвельда [20] с минимизацией производной разности по методике, используемой ранее для ценосфер летучих зол $[6,9]$. Дифракционные данные были получены на порошковом дифрактометре X'Pert Pro MPD (PANalytical, Hидерлан$\partial b l)$ с твердотельным детектором PIXcel и вторичным графитовым монохроматором для $\mathrm{Cu}_{\mathrm{K} \alpha}$ излучения.

Насыпную плотность определяли на автоматизированном анализаторе Autotap (Quantachrome Instruments, США). Морфологию глобул исследовали на порошковых образцах с применением сканирующего электронного микроскопа ТМ-1000 (Hitachi, Япония).

Физико-химические показатели соответствия узких фракций микросфер техническим требованиям, предъявляемым к гранулам алюмосиликатных пропантов, включая сопротивление раздавливанию, растворимость в кислотах, сферичность, округлость были определены по стандартным методикам испытаний согласно ГОСТ Р 51761-2013 [15].

\section{Результаты и обсуждение}

К физико-химическим показателям алюмосиликатных пропантов, влияющих при их использовании на проводимость трещин, относятся гранулометрический состав, насыпная плотность, массовое содержание $\mathrm{Al}_{2} \mathrm{O}_{3}$, сферичность, округлость, растворимость в кислотах, сопротивление раздавливанию [15]. В зависимости от размера частиц пропанты подразделяются на несколько фракций в интервале от 2.0 до 0.2 мм. В частности, гранулы, которые проходят через сито № 40 и задерживаются на сите № 70, образуют фракцию с размером частиц $-0.425+0.212$ мм. Для удовлетворения требования к гранулометрическому составу пропантов [15] из концентратов ценосфер летучих зол и золы-уноса локального отбора были выделены узкие фракции микросфер размером -0.4+0.2 мм, соответствующие фракции пропантов 40/70. Средний диаметр глобул полученных узких фракций находится в интервале 235-328 мкм (табл. 1). Следует отметить, что в энергетических золах от пылевидного сжига-

$$
-251-
$$


Таблица 1. Физико-химические характеристики узких фракций микросфер $-0.4+0.2$ мм

Table 1. Physical and chemical characteristics of narrow fractions of microspheres $-0.4+0.2 \mathrm{~mm}$

\begin{tabular}{|c|c|c|c|c|c|c|}
\hline Параметры & $\mathrm{H}$ & M & $\mathrm{R}$ & HM-R-5A ng & $\mathrm{R} / \mathrm{A} 25 \mathrm{GG}$ & $\mathrm{R} / \mathrm{B} 16 \mathrm{GG}$ \\
\hline \multicolumn{7}{|c|}{ Химический состав, мас. \% } \\
\hline П.п.п. & 1.00 & 2.00 & 0.74 & 0.80 & 0.06 & 0.40 \\
\hline $\mathrm{SiO}_{2}$ & 64.52 & 65.94 & 55.22 & 54.82 & 55.42 & 57.58 \\
\hline $\mathrm{Al}_{2} \mathrm{O}_{3}$ & 21.23 & 25.56 & 37.36 & 39.80 & 37.95 & 30.07 \\
\hline $\mathrm{Fe}_{2} \mathrm{O}_{3}$ & 6.79 & 2.0 & 2.80 & 1.10 & 2.60 & 7.99 \\
\hline $\mathrm{CaO}$ & 2.90 & 1.54 & 1.63 & 1.54 & 1.54 & 1.45 \\
\hline $\mathrm{MgO}$ & 2.31 & 1.60 & 0.83 & 1.09 & 1.22 & 1.09 \\
\hline $\mathrm{SO}_{3}$ & 0.40 & 0.20 & 0,05 & 0.17 & 0.07 & 0.21 \\
\hline $\mathrm{Na}_{2} \mathrm{O}$ & 0.30 & 0.49 & 0.46 & 0.30 & 0.39 & 0.35 \\
\hline $\mathrm{K}_{2} \mathrm{O}$ & 0.40 & 0.32 & 0.90 & 0.21 & 0.61 & 0.50 \\
\hline \multicolumn{7}{|c|}{ Фазовый состав, мас. \% } \\
\hline Стеклофаза & 92.7 & 93.4 & 66.4 & 64.1 & 67.5 & 62.6 \\
\hline Муллит & 1.2 & 3.8 & 31.0 & 34.0 & 30.0 & 27.0 \\
\hline Кварц & 5.5 & 2.2 & 2.4 & 1.7 & 2.3 & 7.6 \\
\hline Кальцит & 0.6 & 0.6 & 0.2 & 0.2 & 0.2 & 0 \\
\hline Феррошпинель & 0 & 0 & 0 & 0 & 0 & 2.8 \\
\hline \multicolumn{7}{|c|}{ Физические характеристики } \\
\hline Средний диаметр, мкм & 328 & 241 & 235 & 241 & 245 & 242 \\
\hline Кажущаяся толщина оболочки, мкм & 15 & 10 & 10 & 13 & 12 & 20 \\
\hline
\end{tabular}

ния углей практически отсутствуют микросферические частицы, соответствующие другим размерным фракциям пропантов [2, 3].

Физико-химические характеристики узких фракций микросфер $-0.4+0.2$ мм представлены в табл. 1, значения физико-химических показателей их соответствия техническим требованиям к алюмосиликатным пропантам согласно ГОСТ Р 51761-2013[15] - в табл. 2.

Одним из ключевых параметров пропантов является насыпная плотность, обеспечивающая равномерное распределение гранул и длительность их присутствия во взвешенном состоянии в жидкости гидроразрыва. Это облегчает удаление жидкости из трещины и ее очистку, увеличивает эффективную длину и дренажную площадь продуктивного пласта, тем самым повышая уровень отдачи скважины [21]. Полученные из зол микросферы характеризуются низкими значениями насыпной плотности в интервале $0.34-0.64$ г/см ${ }^{3}$ (табл. 2). Это определяет перспективность их применения в качестве основы облегченных материалов, а в случае пропантов позволит использовать в качестве жидкости гидроразрыва воду, существенно снижая затраты и способствуя росту экономической эффективности процесса.

Выделенные фракции микросфер характеризуются широким диапазоном изменения химического и фазового составов. Основными компонентами химического состава являются $\mathrm{SiO}_{2}$ и $\mathrm{Al}_{2} \mathrm{O}_{3}$ (55-66 и 21-40 мас. \% соответственно, табл. 1), суммарное содержание которых достигает 86-95 мас. \%. Содержание $\mathrm{Fe}_{2} \mathrm{O}_{3}$ составляет 1-8 мас. \%. По данным количественного 
Таблица 2. Физико-химические показатели узких фракций микросфер $-0.4+0.2$ мм согласно техническим требованиям к алюмосиликатным пропантам по ГОСТ Р 51761-2013 [15]

Table 2. Physical and chemical characteristics of narrow fractions of microspheres $-0.4+0.2 \mathrm{~mm}$ according to the specifications of GOST R 51761-2013 for aluminosilicate proppants [15]

\begin{tabular}{|c|c|c|c|c|c|c|}
\hline \multicolumn{7}{|c|}{ Наименование показателя } \\
\hline Образец & 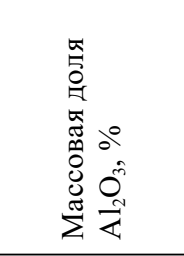 & 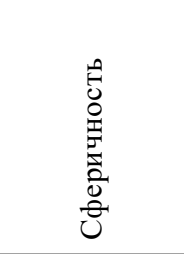 & 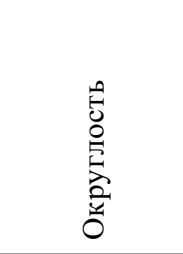 & 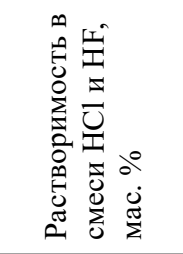 & 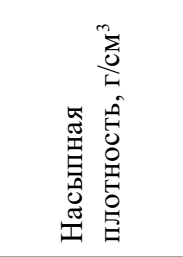 & 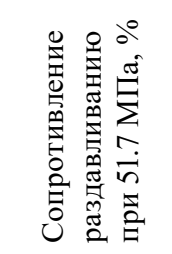 \\
\hline \multicolumn{7}{|c|}{ Требования ГОСТ Р 51761-2013 [15] } \\
\hline $\begin{array}{c}\text { Пропант } \\
40 / 70\end{array}$ & не менее 50 & не менее 0.7 & не менее 0.7 & не более 8.0 & не более 1.9 & не более 5.0 \\
\hline $\mathrm{H}$ & 21.23 & 1.0 & 1.0 & 31 & 0.37 & 85 \\
\hline M & 25.56 & 1.0 & 1.0 & 26 & 0.34 & 94 \\
\hline $\mathrm{R}$ & 37.36 & 1.0 & 1.0 & 27 & 0.36 & 85 \\
\hline HM-R-5A ng & 39.80 & 1.0 & 1.0 & 26 & 0.44 & 80 \\
\hline R/A25 GG & 37.95 & 1.0 & 1.0 & 30 & 0.39 & 80 \\
\hline $\mathrm{R} / \mathrm{B} 16 \mathrm{GG}$ & 30.07 & 0.8 & 0.9 & 21 & 0.64 & 53 \\
\hline
\end{tabular}

рентгенофазового анализа (табл. 1), доля аморфной стеклофазы составляет 63-93, фазы муллита - 1-34, кварца - 2-8, кальцита - 0-1 мас. \%; во фракции R/B16 GG присутствует железосодержащая шпинельная фаза на уровне 3 мас. \%.

Кажущаяся толщина оболочки глобул узких фракций ценосфер составляет 10-15 мкм. Для фракции микросфер R/B16 GG, характеризующейся максимальным значением насыпной плотности -0.64 г $/ \mathrm{cm}^{3}$, значение кажущейся толщины оболочки достигает 20 мкм (табл. 1).

Анализ СЭМ-снимков изученных фракций показал, что они содержат микросферы с непористой гладкой или рельефной внешней поверхностью (рис. 1a,b), глобулы с пористой оболочкой и вспененные частицы с крупными открытыми порами на внешней поверхности (рис. $1 c-f$ ), плотные белые массивные глобулы и темные губчатые частицы (рис. $1 f$ ). Сферичность и округлость частиц полностью соответствует техническим требованиям, предъявляемым к гранулам алюмосиликатных пропантов (табл. 2).

С использованием оптической микроскопии в исследуемых фракциях микросфер идентифицированы основные морфологические типы глобул (табл. 3), отличающиеся строением оболочки. На снимках полированных срезов видно, что оболочка может иметь характерное кольцевое (рис. $2 a$ ), сетчатое (рис. $2 b$ ), массивное (2c) или губчатое $(2 d)$ строение. Среди сфер кольцевого строения различают глобулы со сплошной или пористой оболочкой. Сферы сетчатого строения могут отличаться количеством внутренних полостей и включают менее плотные пенистые или более плотные мелкоячеистые частицы. Так, узкие фракции ценосфер серии Н и М представлены только глобулами кольцевого строения, абсолютное большинство которых сферы с пористой оболочкой - 95-98 об. \%. Узкие фракции ценосфер серии R, наряду с глобулами кольцевого строения с пористой оболочкой, включают около половины или чуть более 

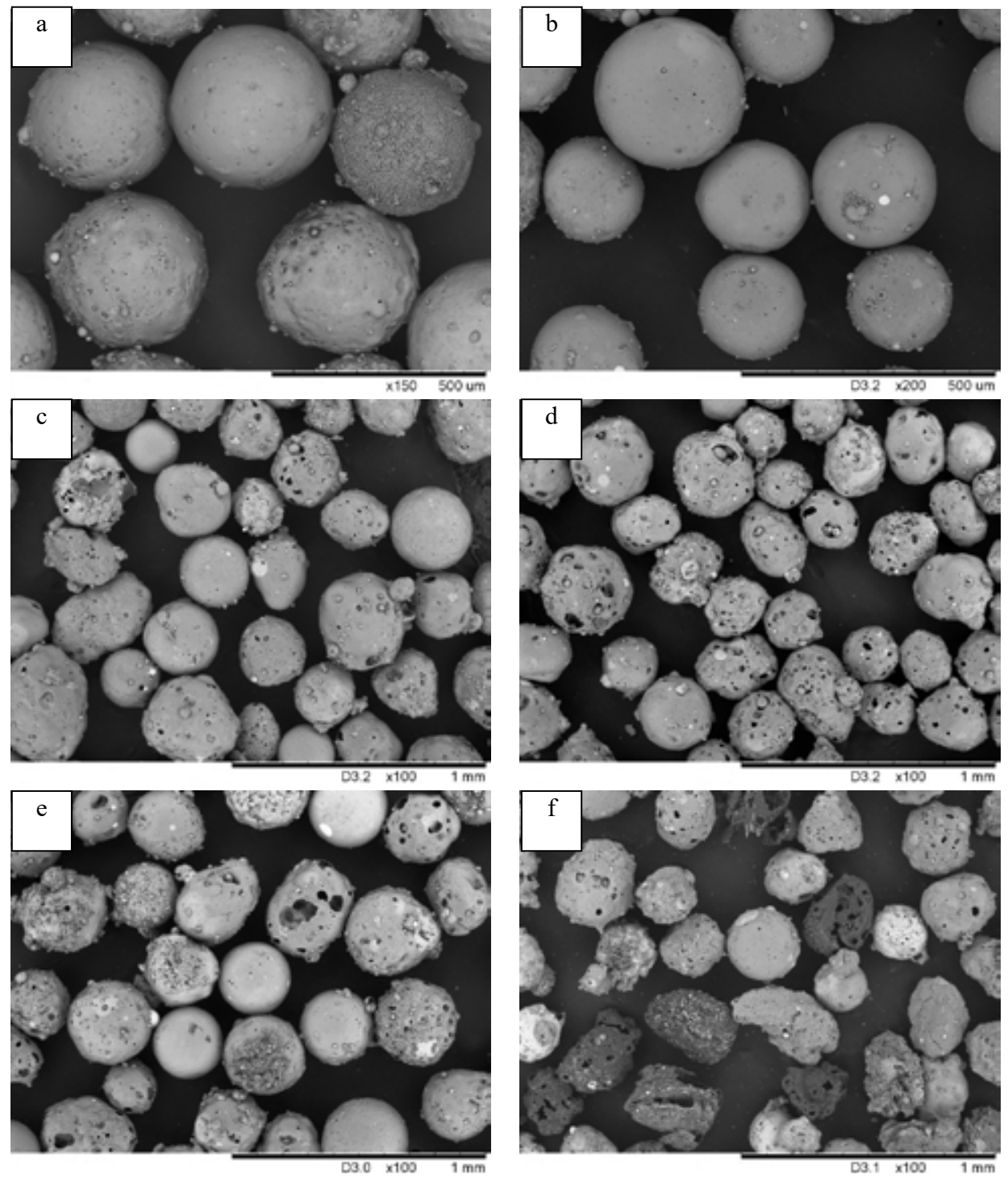

Рис. 1. СЭМ-снимки узких фракций микросфер-0.4+0.2: (a) H, (b) M, (c) R, (d) HM-R-5A ng, (e) R/A25 GG, (f) R/B16 GG

Fig. 1. SEM images of narrow fractions of microspheres $-0.4+0.2$ : (a) H, (b) M, (c) R, (d) HM-R-5A ng, (e) R/A25 GG, (f) R/B16 GG

частиц сетчатого строения (47-60 об. \%) (табл. 3). Фракция микросфер R/B16 GG, выделенная из золы серии $\mathrm{R}$, отличается разнообразием морфологических типов. Сферы кольцевого строения с пористой оболочкой (рис. $3 a$ ) составляют четверть фракции, частицы сетчатого строения (рис. $3 b$ ) содержатся в количестве 39 об. \%, дополнительно идентифицированы массивные плотные сферы белого цвета (рис. $3 c$ ) и губчатые темные частицы (рис. $3 d$ ), составляющие 25 и 11 об. \% соответственно (табл. 3).

Главной проблемой при изготовлении облегченных пропантов является наличие таких взаимоисключающих параметров, как низкое значение насыпной плотности и требуемая высокая прочность гранул. Среди исследуемых микросфер лучшим прочностным показателем 
Таблица 3. Содержание глобул различных морфологических типов (об. \%) в узких фракциях микросфер $-0.4+0.2 \mathrm{мм}$

Table 3. Content of globules of different morphological types (vol. \%) in narrow fractions of microspheres $-0.4+0.2 \mathrm{~mm}$

\begin{tabular}{|cccccc|}
\hline Образец & $\begin{array}{c}\text { Кольцевого строения } \\
\text { со сплошной } \\
\text { оболочкой }\end{array}$ & $\begin{array}{c}\text { с пористой } \\
\text { оболочкой }\end{array}$ & $\begin{array}{c}\text { Сетчатого } \\
\text { строения }\end{array}$ & Массивные & Губчатые \\
\hline H & 1 & 99 & 0 & 0 & 0 \\
M & 4 & 96 & 0 & 0 & 0 \\
R & 3 & 50 & 47 & 0 & 0 \\
HM-R-5A ng & 2 & 38 & 60 & 0 & 0 \\
R/A25 GG & 3 & 45 & 52 & 0 & 0 \\
R/B16 GG & 0 & 25 & 39 & 25 & 11 \\
R/B16 GG/2 & 0 & 7 & 58 & 29 & 6 \\
\hline
\end{tabular}
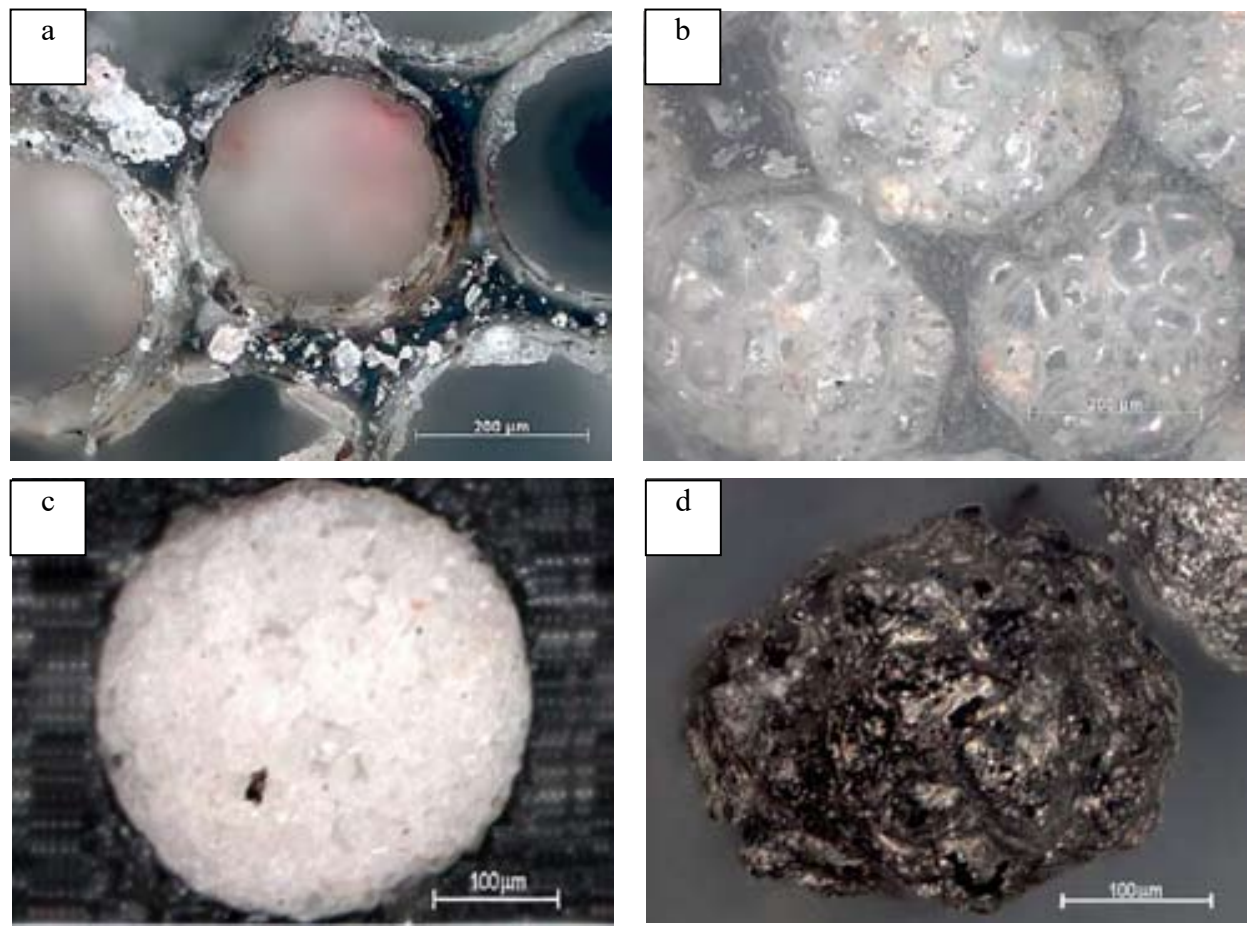

Рис. 2. Снимки полированных срезов микросфер $-0.4+0.2$ с оболочкой кольцевого (a) H, сетчатого (b) R, массивного (c) R/B16 GG и губчатого строения (d) R/B16 GG, по данным оптической микроскопии

Fig. 2. Optical images of polished sections of microspheres $-0.4+0.2$ with a shell of a ring (a) $H$, net-work (b) $R$, solid (c) R/B16 GG and spongy structures (d) R/B16 GG

(53 \%) обладает узкая фракция R/B16 GG (табл. 2), характеризующаяся максимальным значением кажущейся толщины оболочки (табл. 1) и в отличие от других фракций содержащая плотные массивные и губчатые частицы (табл. 3, рис. 3). Для выделения глобул повышенной прочности эта фракция была подвергнута последовательному 2-стадийному воздействию 

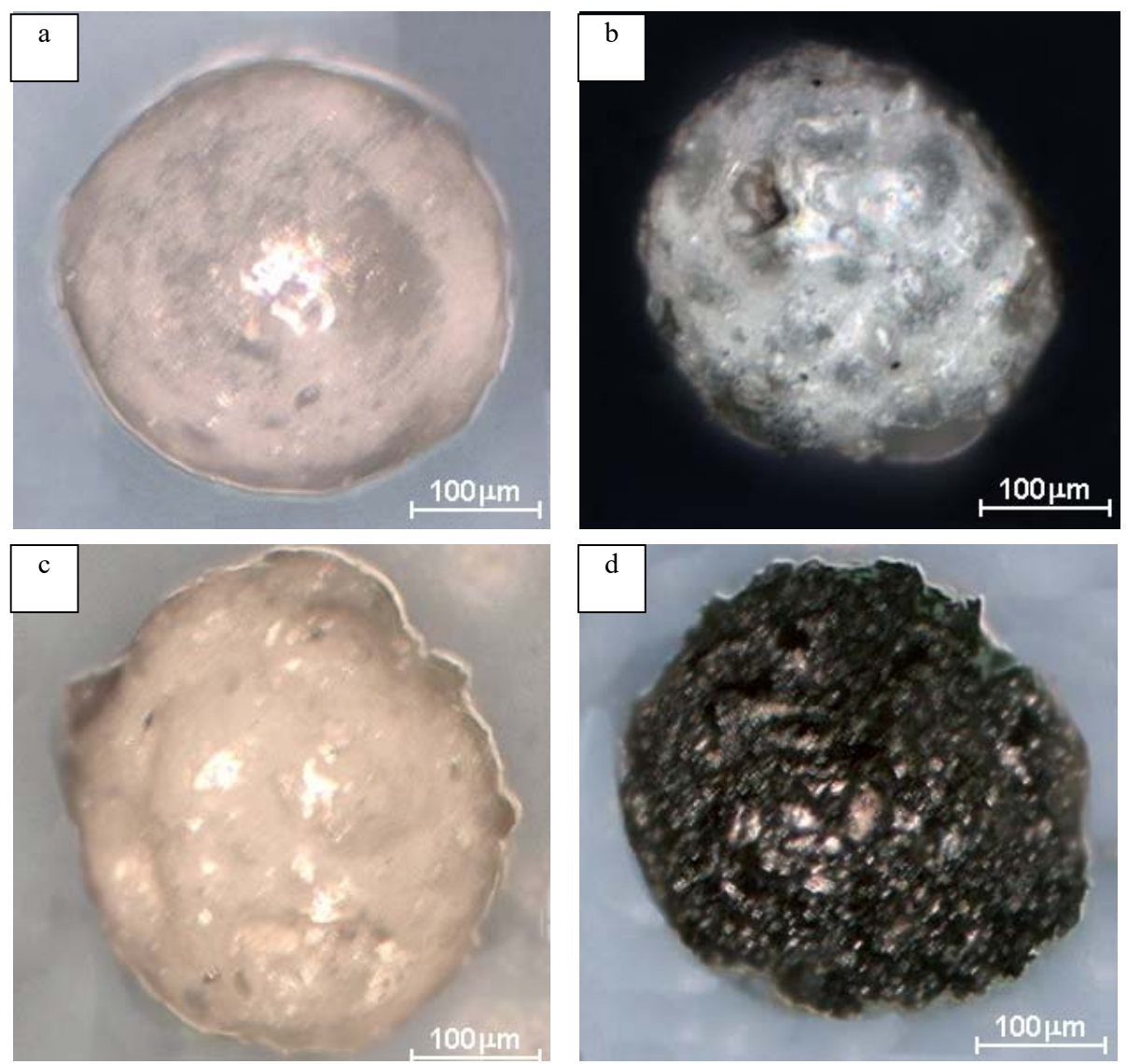

Рис. 3. Снимки микросфер различных морфологических типов фракции R/B16 GG, по данным оптической микроскопии: (a) кольцевого строения с пористой оболочкой, (b) сетчатого строения, (c) плотная массивная, (d) губчатая частица

Fig. 3. Images of microspheres of different morphological types of the fraction R/B16 GG according to optical microscopy data: (a) a single-ring structure with a porous shell, (b) net-work structure, (c) solid structure, (d) spongy particle

сжимающей нагрузки при 51.7 МПа с последующим отделением разрушенных частиц. Установлено, что частицы, оставшиеся неразрушенными после первого воздействия R/B16 GG/1 (рис. $4 a$ ), характеризуются бо́льшими значениями насыпной плотности и кажущейся толщины оболочки по сравнению с исходной фракцией: 0.81 г $\mathrm{cm}^{3}$ и 26 мкм, для исходной фракции 0.64 г/см ${ }^{3}$ и 20 мкм соответственно. При этом прочностные показатели R/B16 GG/1 улучшились до 41 \%. Для глобул, сохранившихся после второго воздействия сжимающей нагрузки R/B16 $\mathrm{GG} / 2$ (рис. $4 b$ ), значения насыпной плотности и кажущейся толщины оболочки увеличились до 0.86 г $/ \mathrm{cm}^{3}$ и 29 мкм соответственно. Анализ основных морфологических типов глобул фракции R/B16 GG/2 показал (табл. 3), что разрушению в первую очередь подвергаются сферы кольцевого строения, а сетчатые и массивные частицы способны оказывать сопротивление раздавливанию даже при последовательном воздействии сжимающей нагрузки. На СЭМ-снимках (рис. 4) видно, что для сохранившихся неразрушенными сетчатых глобул характерно плотное мелкоячеистое строение, обеспечивающее прочностные свойства частиц. 

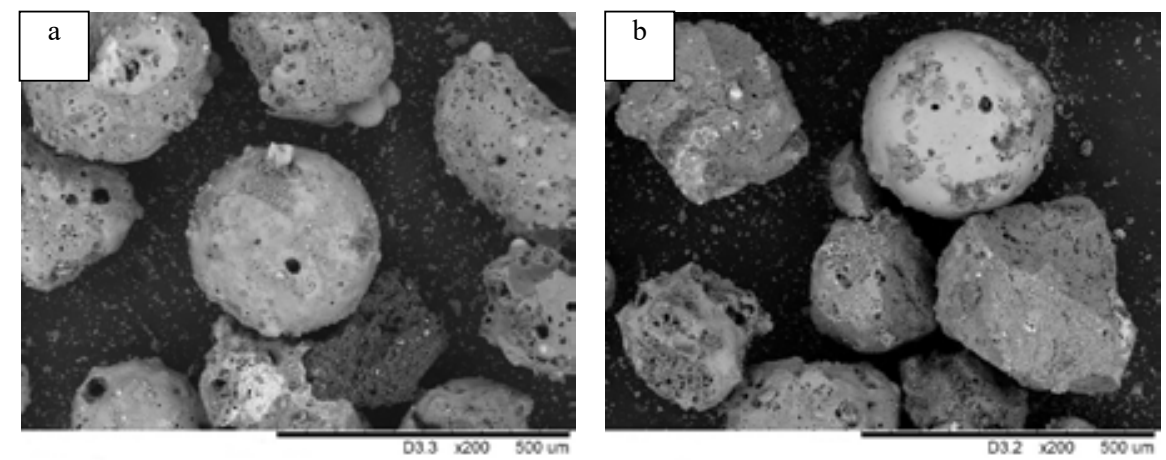

Рис. 4. СЭМ-снимки узкой фракции микросфер R/B16 GG после последовательного воздействия сжимающей нагрузки при 51.7 МПа и отделения разрушенных глобул: (a) R/B16 GG/1, (b) R/B16 GG/2

Fig. 4. SEM images of a narrow fraction of microspheres R/B16 GG after successive exposure to compressive loading at $51.7 \mathrm{MPa}$ and separation of destroyed globules: (a) R/B16 GG/1, (b) R/B16 GG/2

Установленные физико-химические показатели узких фракций микросфер $-0.4+0.2$ мм удовлетворяют техническим требованиям к гранулам алюмосиликатных пропантов [15] по насыпной плотности, сферичности и округлости, превышая допустимые значения для растворимости в кислотах и сопротивления раздавливанию (табл. 2). Благодаря низкой насыпной плотности и возможности выделения частиц повышенной прочности, полученные узкие фракции микросфер потенциально пригодны для получения облегченных композитных материалов, в том числе различных типов синтаксических пен на основе полимеров [22, 23], металлокомпозитов $[24,25]$, керамических материалов $[26,27]$.

\section{Выводы}

Из концентратов ценосфер летучих зол и золы-уноса локального отбора, полученных от пылевидного сжигания разных типов энергетических углей на крупных тепловых станциях России, выделены узкие фракции микросфер размером $-0.4+0.2$ мм с низкой насыпной

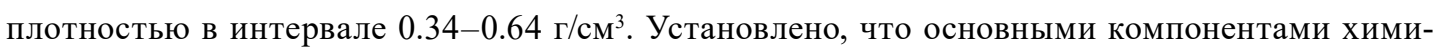
ческого состава полученных узких фракций являются $\mathrm{SiO}_{2}-55-66$ и $\mathrm{Al}_{2} \mathrm{O}_{3}-21-40$ мас. \%. Доля аморфной стеклофазы составляет 63-93, фазы муллита - 1-34, кварца - 2-8, кальцита - 0-1 мас. \%. Основными морфологическими типами глобул являются сферы кольцевого строения с пористой оболочкой, частицы сетчатого строения, массивные плотные сферы и губчатые частицы. Показано, что лучшими прочностными показателями обладает узкая фракция микросфер R/B16 GG, характеризующаяся максимальными значениями насыпной

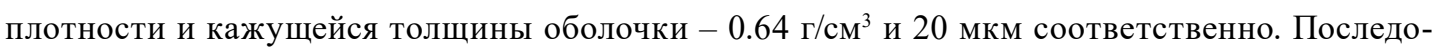
вательное 2-стадийное воздействие сжимающей нагрузки при 51.7 МПа позволило выделить частицы повышенной прочности, для которых значения насыпной плотности и кажущейся толщины оболочки увеличились до 0.86 г $/ \mathrm{cm}^{3}$ и 29 мкм соответственно. Установлено, что разрушению преимущественно подвергаются сферы кольцевого строения, а сетчатые и массивные частицы оказывают большее сопротивление раздавливанию, обеспечивая улучшенные прочностные свойства узких фракций микросфер. Благодаря низкой насыпной плотности и возможности выделения частиц повышенной прочности, полученные узкие фракции микро-

$$
-257-
$$


сфер потенциально пригодны для получения облегченных композитных материалов различного назначения.

\section{Благодарности}

Авторы выражают благодарность сотрудникам ИХХТ СО РАН Л.А. Соловьеву за проведение количественного рентгенофазового анализа, Е.В. Мазуровой за съемку образцов на сканирующем электронном микроскопе, Е.В. Рабчевскому за исследования образцов на оптическом микроскопе.

Исследование выполнено при финансовой поддержке Российского фонда фундаментальных исследований, Правительства Красноярского края, Красноярского краевого фонда науки в рамках научного проекта № 18-43-240002 «Разработка облегченных высокопрочных проппантов на основе узких фракций микросфер энергетических зол» и в рамках проекта фундаментальных исследований СО РАН V.45.3.3 «Формирование новых функциональных микросферических и композитных материалов с заданными свойствами».

\section{Список литературы}

1. Кизильштейн Л.Я., Дубов И.В., Шпицглуз А.Л., Парада С.Г. Компоненты зол и шлаков ТЭЦ. М.: Энергоатомиздат, 1995. 176 с. [Kizil'shtein L.Ya., Dubov I.V., Shpitsgluz A.L., Parada S.G. Components of Power Plant ashes and slag. Moscow: Energoatomizdat, 1995. 176 p. (In Russ.)]

2. Vassilev S.V., Menendez R., Diaz-Somoano M., Martinez-Tarazona M.R. Phase-mineral and chemical composition of coal fly ashes as a basis for their multicomponent utilization. 2. Characterization of ceramic cenospheres and salt concentrates. Fuel 2004. Vol. 83, P. 585-603.

3. Blissett R.S., Rowson N.A. A review of the multi-component utilisation of coal fly ash. Fuel 2012. Vol. 97, P. 1-23.

4. Yao Z.T., Ji X.S., Sarker P.K., Tang J.H., Ge L.Q., Xia M.S., Xi Y.Q. A comprehensive review on the applications of coal fly ash. Earth-Science Reviews 2015. Vol. 141, P. 105-121.

5. Anshits N.N., Mikhailova O.A., Anshits A.G., Salanov A.N. Chemical composition and structure of the shell of fly ash non-perforated cenospheres produced from the combustion of the Kuznetsk coal (Russia). Fuel 2010. Vol. 89(8), P. 1849-1862.

6. Fomenko E.V., Anshits N.N., Solovyov L.A., Mikhaylova O.A., Anshits A.G. Composition and morphology of fly ash cenospheres produced from the combustion of Kuznetsk coal. Energy and Fuels 2013. Vol. 27(9), P. 5440-5448.

7. Fomenko E.V., Anshits N.N., Vasilieva N.G., Mikhaylova O.A., Rogovenko E.S., Zhizhaev A.M., Anshits A.G. Characterization of fly ash cenospheres produced from the combustion of Ekibastuz coal. Energy and Fuels 2015. Vol. 29(8), P. 5390-5403.

8. Fomenko E.V., Rogovenko E.S., Solovyov L.A., Anshits A.G. Gas permeation properties of hollow glass-crystalline microspheres. RSC Advances 2014. Vol. 4(20), P. 9997-10000.

9. Fomenko E.V., Anshits N.N., Pankova M.V., Mikhaylova O.A., Solovyov L.A., Shishkina N.N., Anshits A.G. Influence of the composition and structure of the glass-crystalline shell of cenospheres on helium permeability. Glass Physics and Chemistry 2012. Vol. 38(2), P. 218-227. 
10. Fomenko E.V., Anshits N.N., Solovyov L.A., Vereshchagin S.N., Anshits A.G., Pankova M.V., Fomin V.M. Helium permeability of microspherical membranes based on mullitized cenospheres. Doklady Physical Chemistry 2010. Vol. 435(2), P. 202-204.

11. Anshits A.G., Anshits N.N., Deribas A.A., Karakhanov S.M., Plastinin A.V., Sil'vestrov V.V., Kasatkina N.S., Reshetnyak A.Yu. Detonation velocity of emulsion explosives containing cenospheres. Combustion, Explosion, and Shock Waves 2005. Vol. 41(5), P. 591-598.

12. Fomenko E.V., Anshits A.G., Bobko A.A., Khramtsov V.V., Salanov A.N., Kirilyuk I.A., Grigor'ev I.A. Perforated cenosphere-supported $\mathrm{pH}$-sensitive spin probes. Russian Chemical Bulletin 2008. Vol. 57(3), P. 493-498.

13. Vereshchagina T.A., Vereshchagin S.N., Shishkina N.N., Solovyov L.A., Vasilieva N.G., Anshits A.G. Microsphere zeolite materials derived from coal fly ash cenospheres as precursors to mineral-like aluminosilicate hosts for ${ }^{135,137} \mathrm{Cs}$ and ${ }^{90} \mathrm{Sr}$. Journal of Nuclear Materials 2013. Vol. 437, P. 11-18.

14. Панкова М.В., Фоменко Е.В., Аншиц Н.Н., Верещагина Т.А., Аншиц А.Г. Микросферические носители и сорбенты для процессов, протекающих в агрессивных средах. Химия в интеpecaх устойчивого развития 2010. T. 18(5), C. 593-601. [Pankova M.V., Fomenko E.V., Anshits N.N., Vereshchagina T.A., Anshits A.G. Microspherical supports and sorbents for processes in aggressive media. Chemistry for sustainable development 2010. Vol. 18(5), P. 593-601. (In Russ.)]

15. ГОСТ Р 51761-2013 Пропанты алюмосиликатные. Технические условия. М.: Стандартинформ, 2014. [GOST R 51761-2013 Aluminosilicate proppants. Specifications. Moscow: Standardinform, 2014. (In Russ.)]

16. Liang F., Sayed M., Al-Muntasheri G.A., Chang F.F., Li L.A comprehensive review on proppant technologies. Petroleum 2016. Vol. 2, P. 26-39.

17. Parker M.A., Ramurthy K., Sanchez P.W. New proppant for hydraulic fracturing improves well performance and decreases environmental impact of hydraulic fracturing operations. Society of Petroleum Engineering 2012. SPE 161344.

18. Kushnerova O.A., Akimochkina G.V., Fomenko E.V., Rabchevskii E.V., Anshits A.G. Onestage aerodynamic separation of fly ash from the pulverized combustion of Ekibastuz basin coal. Solid Fuel Chemistry 2018. Vol. 52(3), P. 188-200.

19. ГОСТ 5382-91 Цемент и материалы цементного производства. Методы химического анализа. М.: Изд-во стандартов, 1991. [GOST 5382-91 Cements and materials for cement production. Chemical analysis methods. Moscow: Standards Publishing, 1991. (In Russ.)]

20. Rietveld H. M. A profile refinement method for nuclear and magnetic structures. Journal of Applied Crystallography 1969. Vol. 2, P. 65-71.

21. Al-Muntasheri G.A. A Critical review of hydraulic-fracturing fluids for moderate-to ultralowpermeability formations over the last decade. SPE Prodtion \& Operations 2014. Vol. 29 (4), P. 243-260.

22. Deepthi M.V., Sharma M., Sailaja R.R.N., Anantha P., Sampathkumaran P., Seetharamu S. Mechanicaland thermalcharacteristicsofhighdensitypolyethylene-flycenospherecomposites.Materials \& Design 2010. Vol. 31, P. 2051-2060.

23. Bharath Kumar B.R., Doddamani M., Zeltmann S.E., Gupta N., Ramesh M.R., Ramakrishna S. Processing of cenosphere/HDPE syntactic foams using an industrial scale polymer injection molding machine. Materials \& Design 2016. Vol. 92, P. 414-423. 
24. Dey A., Pandey K.M. Characterization of fly ash and its reinforcement effect on metal matrix composites: A Review. Reviews on Advanced Materials Science 2016. Vol. 44(2), P. 168-181.

25. Wu G.H., Dou Z.Y., Sun D.L., Jiang L.T., Ding B.S., He B.F. Compression behaviors of cenosphere - Pure aluminum syntactic foams. Scripta Materialia 2007. Vol. 56, P. 221-224.

26. Shao Y., Jia D., Zhou Y., Liu B. Novel method for fabrication of silicon nitride/silicon oxynitride composite ceramic foams using fly ash cenosphere as a pore-forming agent. Journal of the American Ceramic Society 2008. Vol. 91, P. 3781-3785.

27. Wang C., Liu J., Du H., Guo A. Effect of fly ash cenospheres on the microstructure and properties of silica-based composites. Ceramics International 2012. Vol. 38, P. 4395-4400. 